\title{
Ischemic stroke after AstraZeneca (Covid-19) vaccination
}

\author{
Muath A. Alammar, MD, PhD.
}

\begin{abstract}
يعتبر التطعيم ضد فيروس كورونا (كوفيد 9 (1) ) استراتيجية وقائية فعالة الإسية

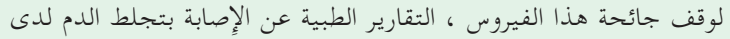

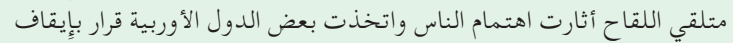

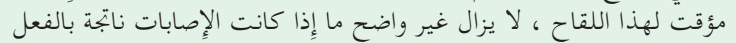

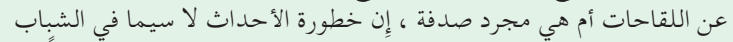

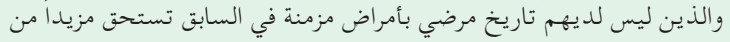

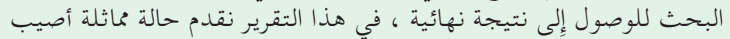

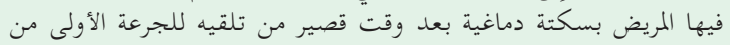
اللقاح.
\end{abstract}

Vaccination against SARS-COV-2 is considered an effective preventive strategy to halt COVID-19 pandemic. Reports of thromboembolic events in vaccine recipients has jolted some of the European countries to pause the vaccination process temporarily. It is still unclear whether the events are actually due to the vaccines or it is just a coincidence. The gravity of events particularly in young and previously normal patients merits further research to reach some conclusion. Here we present a similar case who sustained ischemic stroke shortly after receiving the first dose of his vaccine.

Keywords: Oxford vaccine, AstraZeneca vaccine, COVID-19 pandemic, ischemic stroke

Saudi Med J 2021; Vol. 42 (10): 1136-1139 doi: 10.15537/smj.2021.42.10.20210326

From the Department of Family Medicine, Shaqra College of Medicine, Shaqra University, Shaqra, Kingdom of Saudi Arabia.

Received 26th April 2021. Accepted 14th July 2021.

Address correspondence and reprint request to: Dr. Muath $A$. Almmar, Department of Family Medicine, Shaqra College of Medicine, Shaqra University, Shaqra, Kingdom of Saudi Arabia. E-mail: Alammar.Muath@gmail.com

ORCID ID: https://orcid.org/0000-0001-8743-7253

Disclosure. Authors have no conflict of interests, and the work was not supported or funded by any drug company.
Vaccination against SARS-CoV-2 has been an important breakthrough to manage the COVID-19 pandemic. To date, 4 vaccines has been approved by the European Medical Agency based on randomized controlled trials: Pfizer/BioNTech, Moderna, AstraZeneca, and Janssen. ${ }^{1}$ By the June 14, 2021 approximately 2.4 billion doses of vaccines have been administered worldwide (COVID-19 Vaccinations Statistics and Research - Our World in Data).

Unusual thromboembolic events were reported in patients who received vaccination against COVID-19. ${ }^{2}$ Based on these preliminary reports of thromboembolic events, some European countries paused Oxford AstraZeneca COVI-19 vaccination. ${ }^{3}$ Here we present a case of ischemic stroke post Oxford AstraZeneca COVID-19 vaccination. Is the vaccine responsible for ischemic stroke in this patient or it is mere a coincidence is yet to be determined?

Case Report. A 43-year old male patient presented with right-sided sudden onset, upper, and lower limb weakness of the body after 3 days of receiving the first dose of AstraZeneca vaccine against COVID-19. Past medical and family history of the patient was unremarkable for hypertension, diabetes, epilepsy, thrombophilia disorders, or any other chronic illnesses. He never smoked and denied chronic use of any drug.

Clinical findings. Power in right lower and upper limb was $3 / 5$ on presentation that improved over a period of 2 days to $4 / 5$, tone was increased, reflexes were brisk on the right side and the right sided plantar had extensor response. Left upper and lower limbs were having normal power, tone, and reflexes. Speech, gag reflex, and rest of the neurological as well as systemic examination was unremarkable.

Diagnostic assessment. Computed tomography brain without contrast carried out at the time of presentation was reported normal, followed by a magnetic resonance (MR) of the brain that was suggestive of ischemic stroke on the left side of the brain (Figures $1 \& 2$ ). The key clinical and laboratory findings for this patient are summarized in Table 1. 
Therapeutic intervention. Patient was started on usual antiplatelets and statins therapy. Thrombolytic therapy was not considered as he presented beyond the window period.

Follow-up and outcome. Patient was followed-up regularly and was improving on both medical and physiotherapy treatment (Figure 3).

Discussion. Beginning in late February 2021 several cases of unusual thromboticembolic events were observed in patients after COVID-19 vaccination which led to the decision of temporarily pausing vaccination in several European countries by the mid of March 2021. ${ }^{3}$ Though according to the European Medicines Agency's (EMA) statement, the number of events were not higher than the incidence of events seen in general population as an observed to expected analysis of events didn't identify an increased risk. ${ }^{4}$

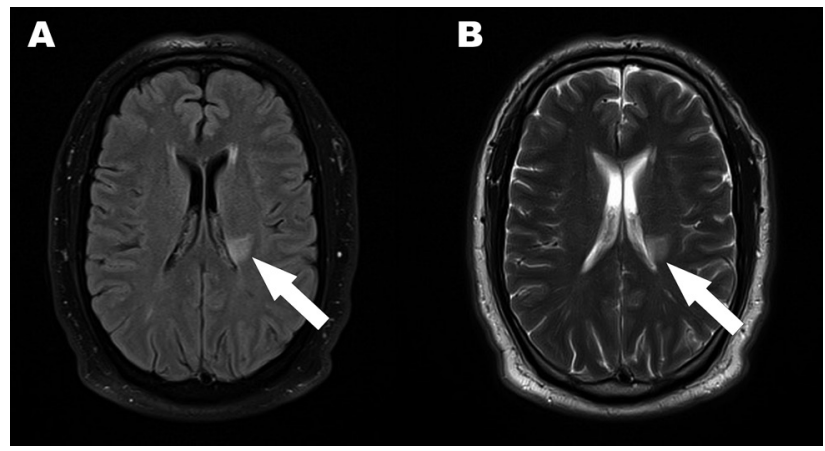

Figure 1 - Magnetic resonance of the brain. A) Fluid attenuated inversion recovery and B) T2 images showing hyperintensities at left paraventricular parietal region.

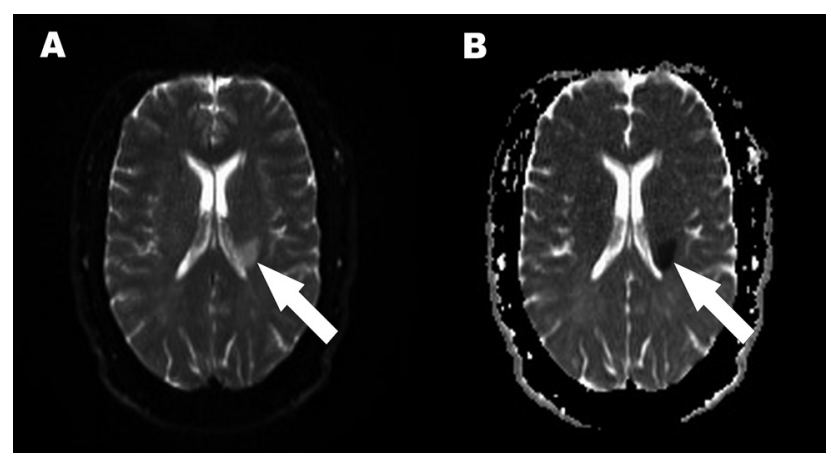

Figure 2 - Magnetic resonance imaging of the brain. A) Diffusion weighted and B) apparent diffusion coefficient showing diffusion restriction in left paraventricular parietal region signifying acute ischemia.
Table 1 - Clinical and laboratory parameters.

\begin{tabular}{lc}
\hline Parameter & Values \\
\hline Height & $170 \mathrm{~cm}$ \\
Weight & $110 \mathrm{~kg}$ \\
Body mass index & $38 \mathrm{~kg} / \mathrm{m}^{2}$ \\
Blood pressure at arrival & $190 / 110 \mathrm{mmHg}$ \\
Haemoglobin & $14.1 \mathrm{~g} / \mathrm{dl}$ \\
Platelets count & $218^{*} 10^{9} / \mathrm{L}$ \\
White blood cells & $8300^{*} 10^{9} / \mathrm{L}$ \\
Low-density lipoprotein & $48 \mathrm{mg} / \mathrm{dl}$ \\
High-density lipoprotein & $28.7 \mathrm{mg} / \mathrm{dl}$ \\
Cholesterol & $141 \mathrm{mg} / \mathrm{dl}$ \\
Triglyceride & $320 \mathrm{mg} / \mathrm{dl}$ \\
\hline
\end{tabular}

Patients with severe COVID-19 infection are at increased risk of developing ischemic stroke, other arterial and venous thromboembolisms because of high grade inflammatory response seen in severe SARS COV-2 infection developing a hypercoagulable state. ${ }^{5}$ But is it the only mechanism of hypercoagulability or there are some other mechanisms involved which may be common between infection and vaccination?

Stroke following varicella and influenza vaccination has been described in the literature and it has been hypothesized that these vaccines, similar to their natural infections, might cause cerebral angiopathy resulting in narrowing and occlusion of the vessels leading to ischemic stroke. ${ }^{6}$ The concern is that similar possible unknown mechanisms may be involved in the AstraZeneca vaccines, causing hypercoagulable state leading to thromboembolisms.

A number of cases from Norway and Germany with thrombocytopenia and thromboses at unusual sites were noted in patients after one week of receiving the Oxford-AstraZeneca vaccines. ${ }^{7,8}$ Another study with similar complications was associated with Johnson \& Johnson. ${ }^{9}$ Johnson $\&$ Johnson is an adenovirus vector vaccine similar to Oxford-AstraZeneca vaccines. Here, the pathophysiologic mechanism postulated was "spontaneous heparin induced thrombocytopenia" as the cause of thromboembolic events. It has been termed as vaccine induced prothrombotic immune thrombocytopenia in order to differentiate it from heparin induced thrombocytopenia. ${ }^{1}$ This may not be the case in our patient because the platelets count was normal.

The presence of an association may not necessarily imply causality particularly when the number of observed thromboembolic events in vaccinated patients are much lower than expected as calculated in comparison 


\section{3 years old healthy male patient}

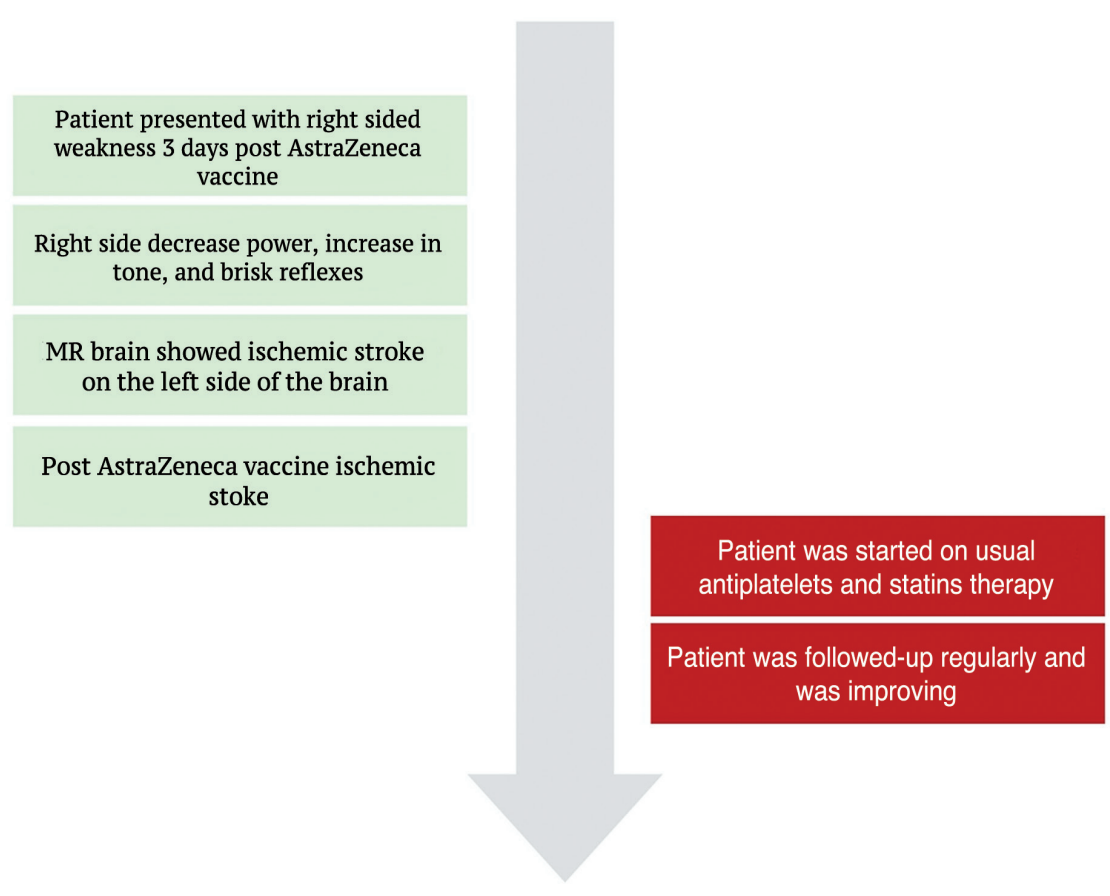

Figure 3 - Case timeline. MR: magnetic resonance

to the incidence of events in general population. ${ }^{4}$ These comparisons were made in Danish population by analyzing the incidence rate of thromboembolic events in vaccinated patients to the natural incidence rate of events in general population prior to the start of vaccination. $^{2}$

Study limitation. There is a lack of comparability between the observed and background populations, lack of further stratification based on age and gender were observed. That is why the inferences drawn cannot be generalized.

The burden of SARS-COV-2 infection is quite significant keeping in view its infectivity, rate of hospitalization, the morbidity and mortality it causes and the economic and financial implications it has on the globe. Therefore, the vaccination against this virus seems to be the most effective method to control this infection and prevent its complications. The incidence of stroke in our patient (and other thromboembolic events reported in other patients) following vaccination will not change our stance in recommending vaccination against SARS-COV-2 infection to control COVID-19 pandemic but we have to be careful in choosing the type of vaccine because as stated by the EMA, "The benefits of vaccination still outweigh the risks of blood clots". ${ }^{10}$

In conclusion, as serious cases of thromboembolisms associated with Oxford-AstraZeneca vaccines, though in small number has been reported and now become more and more, in some cases with combination of thrombocytopenia and bleeding, it is become concerning and need further action to be taken and further investigations to be sure.

Acknowledgment. I would like to thank Dr. Mohammed Shabbir, Department of Medicine, Shaqra University, Shaqra, Kingdom of Saudi Arabia for his help in manuscript reviewing and editing. I would like also to thank Editage (www.editage.com) for English language editing.

\section{References}

1. Greinacher, A., Thiele, T., Warkentin, T. E., Weisser, K., Kyrle, P. A., \& Eichinger, S. Thrombotic thrombocytopenia after ChAdOx1 nCov-19 vaccination. N Engl J Med 2021; 384: 2092-2101.

2. Østergaard SD, Schmidt M, Horváth-Puhó E, Thomsen RW, Sørensen HT. Thromboembolism and the Oxford-AstraZeneca COVID-19 vaccine: side-effect or coincidence? Lancet 2021; 397: 1441-1443. 
3. Wise J. Covid-19: European countries suspend use of OxfordAstraZeneca vaccine after reports of blood clots. BMJ 2021; 372: n699.

4. European Medicines Agency. Signal assessment report on embolic and thrombotic events (SMQ) with COVID-19 Vaccine (ChAdOx1-S [recombinant]) - COVID-19 Vaccine AstraZeneca (Other viral vaccines). [Updated 2021; Accessed 2021 April 21]. Available from: https://www.ema.europa.eu/en/ documents/prac-recommendation/signal-assessment-reportembolic-thrombotic-events-smq-covid-19-vaccine-chadox1-srecombinant-covid_en.pdf

5. Morassi M, Bagatto D, Cobelli M, D'Agostini S, Gigli GL, Bnà C, Vogrig A. Stroke in patients with SARS-CoV-2 infection: case series. J Neurol 2020; 267: 2185-2192.

6. Thoon KC, Chan DW. Childhood stroke after influenza vaccination. SAGE 2012; 21: 297-300.
7. Schultz NH, Sørvoll IH, Michelsen AE, Munthe LA, LundJohansen F, Ahlen MT, Wiedmann M, Aamodt AH, Skattør TH, Tjønnford GE, Holme PA. Thrombosis and thrombocytopenia after ChAdOx1 nCoV-19 vaccination. N Engl J Med 2021; 384: 2124-2130.

8. Greinacher A, Thiele T, Warkentin TE, Weisser K, Kyrle PA, Eichinger S. Thrombotic thrombocytopenia after ChAdOx1 nCov-19 vaccination. $N$ Engl J Med 2021; 384: 2092-2101.

9. Muir KL, Kallam A, Koepsell SA, Gundabolu K. Thrombotic thrombocytopenia after Ad26. COV2. S vaccination. $N$ Engl J Med 2021; 384: 1964-1965.

10. European Medicines Agency. COVID19 vaccine AstraZeneca benefits still outweigh the risks despite possible link to rare blood clots with low blood platelets. [Updated 2021 March 18. Accessed 2021 April 23]. Available from: https://www.ema. europa.eu/en/news/covid-19-vaccine-astrazeneca-benefits-stilloutweigh-risks-despite-possible-link-rare-blood-clots 